\title{
Psychometric properties of the Iranian version of Wijma delivery expectancy / experience questionnaire in women who experience fear of childbirth: version $B$
}

\author{
Zahra Abbaspoor, Mohammad Hosein Haghighizadeh, Parvin Abedi \\ Corresponding author: Dr. Parvin Abedi, 13th East Kianpars Ave, 1st Eastern Maroon St, No: 46, \\ Ahvaz, Iran; Email : parvinabedi@ymail.com
}

Distributed under Attribution-Non Commercial - Share Alike 4.0 International (CC BY-NC-SA 4.0)

\begin{abstract}
Objectives: This study aimed to explore the psychometric properties of the Wijma delivery expectancy / experience questionnaire (WDEQ-B): Iranian version. Methods: In this cross-sectional study 660 women in the postpartum period were recruited in Ahvaz, Iran from May 2017 to October 2017. A sociodemographic questionnaire, a WDEQ $\mathrm{B}$ questionnaire, Beck depression (BAI) and depression, stress, and anxiety (DASS) questionnaires were used to gather information. The experts used the forward-backward process to the translation of the WDEQ - B. The exploratory factor analyses, Cronbach's alpha, Pearson correlation, and independent t-test were used to analyze data. Results: Cronbach's alpha for all factors except for concerns for the baby $(\alpha=0.50)$ and lack of positive behaviors $(\alpha=0.60)$, was more than 0.71 . The W-DEQ - B was found to have six factors including lack of positive feelings, fear and pain, concerns about childbirth, loneliness, lack of positive behaviors, and concerns for the baby. They explained $52 \%$ of the overall variance and there was a positive correlation between WDEQ-B and BAI, DASS questionnaires. Conclusions: Persian version of WDEQ-B is a valid and reliable questionnaire to use among Iranian women.
\end{abstract}

Keywords: Childbirth experience, fear of childbirth, psychometrics, properties.

Fear of childbirth (FOC) is one of the factors that can affect women physically and emotionally. FOC or tokophobia is classified as primary and secondary. Primary tokophobia is more prevalent in nulliparous women, while secondary is more prevalent in women who experienced a traumatic vaginal delivery. ${ }^{1}$

Iran has a high rate of cesarean section (CS) around 48\%. Sociodemographic, obstetrical and medical factors including fear, with the highest rate, are contributing to this high prevalence. ${ }^{2}$ Among 40 pregnant women who died during pregnancy or 42 days postpartum, $55 \%$ of maternal death were contributed to CS, compared to only $20 \%$ in vaginal birth. $^{3}$ Also, around $6-10 \%$ of primigravida women experience severe fear of childbirth. ${ }^{4}$ In Australia, out of $24 \%$ of women having fear of childbirth, $31.5 \%$ had a severe FOC. ${ }^{5}$ Severe FOC can urge women to postpone or avoid their pregnancy ${ }^{6}$ or request an elective cesarean section. ${ }^{7}$ It also can increases the risk of postpartum depression, ${ }^{8}$ decreases the positive feelings to pregnancy and childbirth and also increases the rate of epidural anesthesia during the labor. ${ }^{9}$

In recent decades, maternal demand for CS has increased. The rate that has reported in Australia (6.4\%), ${ }^{10}$ in Sweden it is $8.2 \%$, and in the United Kingdom it is $7 \% .^{11,12}$ In a study conducted in Iran, Tehran, the rate of elective cesarean was $72 \%, 22 \%$ of which was made on maternal request. ${ }^{13}$ Maternal demand for caesarean in Iran is more than twice that of developing countries. Therefore, to avoid that fear of childbirth, it is important to screen pregnant women and to design an intervention to make childbirth a pleasant event for women. So for childbearing women to be screened and cared for, a reasonable scale is required to assess and quantify fear

Received: $20^{\text {th }}$ July 2020, Peer review completed: $25^{\text {th }}$ September 2020, Accepted: $1^{\text {th }}$ October 2020.

Abbaspoor Z, Hosein Haghighizadeh M, Abedi P. Psychometric properties of the Iranian version of Wijma delivery expectancy / experience questionnaire in women who experience fear of childbirth: version B. The New Indian Journal of OBGYN. 2021; 8(1): 39-45. 
of childbirth.

Wijma delivery expectancy/experience questionnaire conceptualized as a unidimensional instrument for measuring fear of childbirth. ${ }^{14}$ Garthus Niegel et al, evaluated this tool in 1642 pregnant women and concluded that this scale is a multidimensional structure with six factors including; fear, negative appraisal, loneliness, lack of self-efficacy, lack of positive anticipation and concerns for the newborn. ${ }^{15} \mathrm{~B}$ Version of WDEQ also measures the postpartum fear. Both versions were translated into different languages. ${ }^{16,17}$

The validity and reliability of the Persian version of WDEQ version A have already been done in Persian language. ${ }^{18}$ This study aimed to explore psychometric properties of WDEQ version B among Iranian reproductive aged women.

\section{Materials and methods}

Participants and procedure: This cross-sectional study was conducted on 660 women (330 primiparous and 330 multiparous women) during the postpartum period. For calculating the sample size, the ratio of questionnaire items to respondent numbers was used. It is 3 to 4 people per item, and can be a maximum of 10 people per item. ${ }^{19}$ Therefore, in the present study, considering that the number of tool items was 33, the maximum sample size (10 times of the questionnaire items) was estimated to be 660 women.

The women were hospitalized in postpartum ward of the two educational hospitals or referred to health centers of Ahvaz, Iran, during postpartum period, from May 2017 to October 2017. The inclusion criteria were; women of reproductive age, women with basic literacy, spontaneous vaginal delivery with a healthy newborn following a singleton pregnancy. Excluding criteria were; high risk pregnancy (pre-eclampsia, gestational diabetes, spotting or bleeding during pregnancy and history of admission to hospital due to medical disorders during pregnancy, depression in a previous pregnancy, on chronic medications, history of chronic disease and with a history of a critical event in the close family members in the last year. Women during their first 30 days of postpartum period, in wards or public health centers, when they referred to test their babies for postnatal screening, and after obtaining the written consent and briefing them about the goals of the study, as well as after confidentiality assurance, were asked to fill out the socio-demographic and WDEQ-B, BAI and DASS II questionnaires.

The questionnaires: WDEQ-B is a 33-item questionnaire that contains six subscales: lack of positive behaviors, concerns about labor pain, concerns about childbirth, loneliness, lack of positive feelings and concerns about the baby. The total score ranged from 0 to 165 and scores $>85$ indicated clinical fear of childbirth ${ }^{14}$.

The Beck depression inventory (BAI) is a 21-item questionnaire with a total score of 0 to 63 . The higher scores show a higher level of depression. ${ }^{20}$ Kaviani and Mousavi approved the validity and reliability of this questionnaire in Iran. $^{21}$ The DASS questionnaire measures depression, stress, and anxiety. The total score of this 42 -item scale is 0 to 63 . Its validity and reliability confirmed by Asghari et al in Iran. $^{22}$

Translation and cultural adaptation: We used a forwardbackward translation procedure. At first, the original questionnaire of WEDQ-B was translated into the persian language by two independent translators who were fluent in persian and english language. The two persian translations were compared and two other translators did the backtranslation into the english language. Then, the researchers and an expert in psychometry reviewed the translation, the face, and the content validity processes and finally, the final version was provided.

Statistical analysis -

Face validity: The face validity of the questionnaire including qualitative and quantitative validity, can help the respondents in filling out a questionnaire, identify any inappropriate items and any ambiguities in the wording of questions. ${ }^{23}$ For evaluating the qualitative face validity of WDEQ, 10 interviews performed with women for ensuring the linguistic and conceptual equivalence of the translations. Also, to determining how long the questionnaire takes to complete and according to the results and based on research team opinions, necessary changes were made and the final version of the questionnaire was obtained. Also, the quantitative face validity test using impact score was measured.

Content validity: For measuring the qualitative content validity, ten experts in reproductive health and obstetrics who were familiar with psychometric process and English language, provided their views on the accuracy of content, position and grammar of items and using the appropriate words in phrases. The content validity ratio (CVR) using item importance and accuracy and the content validity index (CVI) including relevancy, clarity, and simplicity of the items were also evaluated. Based on the Lawshe table and a group composed of 10 experts, a minimum CVR of 0.62 was acceptable. ${ }^{24}$ The Lawshe table and the view of experts also 
were used for measuring $\mathrm{CVII}^{25}$ The $\mathrm{I}-\mathrm{CVI} \geq 79 \%$ was considered appropriate. ${ }^{26-27}$

Construct validity: Factor analysis: Exploratory factor analysis (EFA) with varimax rotation was used for determining the internal consistency of WEDQ-B. ${ }^{28}$ An eigenvalue $>1.2$ and a factor loading $\geq 0.4$ and scree plot were applied to determine the best structure (figure-1). ${ }^{29-30}$ The Cronbach's alpha coefficient value $\geq 0.70$ was considered as satisfactory internal consistency for the scale. ${ }^{31-32}$

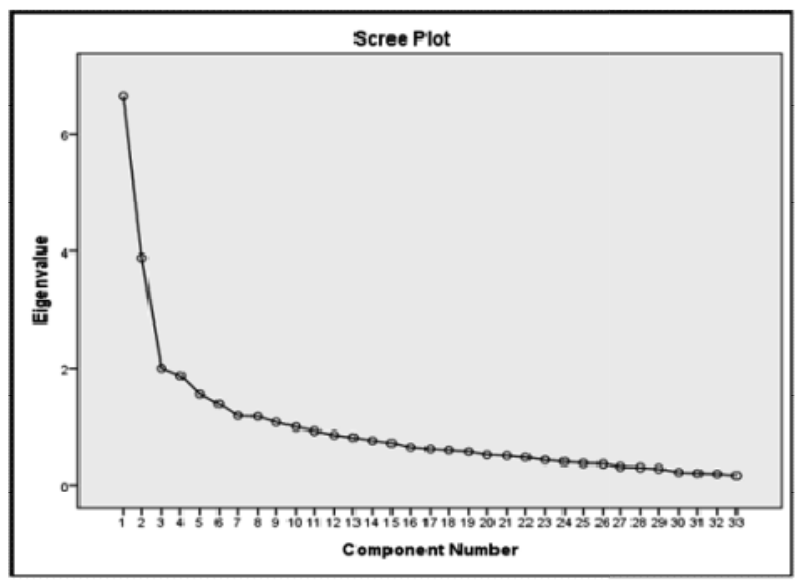

Figure 1: Scree plot of eigenvalues for principal components analysis of WEDQ-B

Concurrent validity: The currently available instrument is the only tool used to screen fear of childbirth but there are some other questionnaires such as BAI and DASS that measuring stress and anxiety. ${ }^{20,33}$

Reliability: To evaluate the test-retest reliability of the WEDQ-B, using convenience sampling method, 30 participants, randomly selected and completed the Persian WEDQ-B at first time and again 4 weeks later, in the same manner. The agreement level was considered as small $(00-$ $0.2)$, as fair $(0.21-0.40)$, as moderate $(0.41-0.60)$, as substantial $(0.61-0.80)$ and as almost perfect $(0.81-1) .{ }^{34}$ The Statistical Package version 23.0 (SPSS, Inc., Chicago, IL, USA) was used for analyzing the data. The relationship between the Persian version of the WEDQ-B with BAI and DASS II questionnaires was determined. Quantitative variables were described by the mean (SD) and categorical variables were also provided by frequency and percentage. Independent t-test was used to evaluate the mean (SD) of women age and the Chi-square test was used to evaluate the categorical variables between the two groups of women. A confidence interval of $95 \%$ and a P-value $<0.05$ was considered as significant.

\section{Results}

A total numbers of 660 women were participated in this study. The age of participants was $22.53 \pm 5.45$ years and $36.67 \pm 4.90$ years $(\mathrm{p}=0.001)$ in nulliparous and multiparous women respectively. Most primiparous women had secondary education $(30 \%)$, while most multiparous women had primary education $(33 \%)(\mathrm{p}=0.32)$. Most women in both groups were housewives and did not have a history of abortion. The two groups did not have a significant difference regarding demographic characteristics except for

\begin{tabular}{|c|c|c|c|}
\hline \multirow[t]{3}{*}{ Variables } & Primiparous & Multiparous & Pvalue \\
\hline & $\mathbf{N}=\mathbf{3 3 0}$ & $\mathbf{N}=\mathbf{3 3 0}$ & \\
\hline & \multicolumn{3}{|c|}{ Mean \pm SD or N (\%) } \\
\hline Age in years & $22.53 \pm 5.45$ & $36.67 \pm 4.90$ & 0.001 \\
\hline \multicolumn{4}{|l|}{ Education } \\
\hline Primary & $91(27.6)$ & $109(33.0)$ & \\
\hline Secondary & $99(30.0)$ & $89(27.0)$ & 0.32 \\
\hline High school & $88(26.7)$ & $88(26.7)$ & \\
\hline University & $52(15.8)$ & $44(13.3)$ & \\
\hline \multicolumn{4}{|c|}{ Spouse's education } \\
\hline Primary & $85(25.7)$ & $96(29.0)$ & 0.66 \\
\hline Secondary & $69(21.0)$ & $70(21.2)$ & \\
\hline High school & 111(33.7) & $100(30.4)$ & \\
\hline University & $65(19.5)$ & $64(19.4)$ & \\
\hline \multicolumn{4}{|l|}{ Job } \\
\hline House-maker & $309(93.7)$ & $315(95.4)$ & 0.19 \\
\hline Worker & $9(2.7)$ & $9(2.8)$ & \\
\hline Employee & $10(3.0)$ & $5(1.5)$ & \\
\hline Self-employed & $2(0.6)$ & $1(0.3)$ & \\
\hline \multicolumn{4}{|l|}{ Spouse's job } \\
\hline Worker & $38(11.5)$ & $50(15.1)$ & 0.24 \\
\hline Employee & $31(9.4)$ & $46(14.0)$ & \\
\hline Self-employed & $188(57.0)$ & $150(45.5)$ & \\
\hline Jobless & $73(22.1)$ & $84(25.4)$ & \\
\hline \multicolumn{4}{|c|}{ History of abortion } \\
\hline 0 & $290(87.9)$ & $247(74.8)$ & 0.001 \\
\hline 1 & $37(11.2)$ & $60(18.1)$ & \\
\hline$\geq 2$ & $3(0.9)$ & $23(7.1)$ & \\
\hline \multicolumn{4}{|c|}{ Neonate's gender } \\
\hline Male & $176(53.3)$ & $195(59.0)$ & 0.07 \\
\hline Female & $154(46.7)$ & $135(41.0)$ & \\
\hline
\end{tabular}

age and history of abortion. Also, the results indicate that $471(71.4 \%)$ of women did not have FOC (score $<100)$, $14.1 \%$ of women had clinical FOC and $14.5 \%$ had extreme FOC before childbirth (score $\geq 185$ ) (table 1$)$.

Face validity: Most of the items were clarified and only 3 to 4 items needs to be changed. The time for completion of the questionnaire was around $10 \mathrm{~min}$. All items were important from the viewpoints of the target group. 


\begin{tabular}{|c|c|c|c|c|c|c|}
\hline Parameters & $\begin{array}{l}\text { Lack of positive } \\
\text { feelings } \\
(\alpha=0.82)\end{array}$ & $\begin{array}{l}\text { Fear and } \\
\text { pain } \\
(\alpha=0.80)\end{array}$ & $\begin{array}{l}\text { Concerns about } \\
\text { childbirth } \\
(\alpha=0.71)\end{array}$ & $\begin{array}{l}\text { Loneliness } \\
(\alpha=0.75)\end{array}$ & $\begin{array}{l}\text { Lack of positive } \\
\text { behaviors } \\
(\alpha=0.60)\end{array}$ & $\begin{array}{l}\text { Concerns for } \\
\text { the baby } \\
(\alpha=0.50)\end{array}$ \\
\hline 18.Нарpy & .791 & & & & & \\
\hline 16. Composed & .731 & & & & & \\
\hline 13.Glad & .721 & & & & & \\
\hline 17.Relaxed & .687 & & & & & \\
\hline 10. Independent & .607 & & & & & \\
\hline 9. Safe & .487 & & & & & \\
\hline 22. Self- confident & .455 & & & & & \\
\hline 14. Proud & .446 & & & & & \\
\hline 4. Strong & .444 & & & & & \\
\hline 5.Confident & .433 & & & & & \\
\hline 1.Fantastic & .323 & & & & & \\
\hline 19.Panic & & .703 & & & & \\
\hline 2.Frightful & & .689 & & & & \\
\hline 6. Afraid & & .622 & & & & \\
\hline 24.Pain & & .603 & & & & \\
\hline 11.Desolate & & .589 & & & & \\
\hline 31.Dangerous & & .578 & & & & \\
\hline 12.Tense & & .550 & & & & \\
\hline 29.Natural & & & .816 & & & \\
\hline 28.Joyful & & & .720 & & & \\
\hline 30.As expected & & & .699 & & & \\
\hline 23.Trust & & & .447 & & & \\
\hline 21.Longing for child & & & .390 & & & \\
\hline 7.Deserted & & & & .766 & & \\
\hline 3.Lonely & & & & .708 & & \\
\hline 15.Abandoned & & & & .657 & & \\
\hline 8.Weak & & & & .473 & & \\
\hline 20.Hopelessness & & & & .427 & & \\
\hline 26.Control & & & & & .700 & \\
\hline 25.Behaved badly & & & & & .700 & \\
\hline 27.Lose my control & & & & & .520 & \\
\hline 32.Fantasies that child will die & & & & & & .889 \\
\hline 33.Fantasies that child will be Injured & & & & & & .882 \\
\hline
\end{tabular}

Content validity: According to the Lawshe table and based on 10 expert's opinions, CVR was 0.84 for the scale and for each item it was $>0.62$ (22) that indicates the necessity and importance of the relevant items in the questionnaire. Also, a high CVI score (0.93) for the total scale, showed satisfactory content validity, although, some items were modified slightly based on expert suggestions.

Factor analysis: The W-DEQ-B questionnaire was analyzed by principal component factor analysis with varimax rotation. The Kaiser-Meyer-Olkin test confirmed the suitability of the data for factor analysis. The overall KaiserMeyer-Olkin score was 0.77 and the variables were correlated with each other. Bartlett's test of sphericity was significant $(\mathrm{P}<0.001)$. The Cronbach's alpha for the scale was 0.83 , indicating good reliability (table 2 ).
The W-DEQ-B had six factors with $52 \%$ of the overall variance. Also, the variance explained by each factor was $11.81 \%$ for lack of positive feelings, $11.59 \%$ for fear and pain, $8.46 \%$ for concerns about childbirth, $7.57 \%$ for loneliness, $6.31 \%$ for lack of positive behaviors and $5.77 \%$ for concerns for the baby. Cronbach's alpha for all factors except for concerns for the baby $(\alpha=0.50)$ and lack of positive behaviors $(\alpha=0.60)$, was $>0.71$ that indicated good internal consistency. The factor loadings of all items exceed 0.323 .

Concurrent validity: The concurrent validity of the $\mathrm{W}$ DEQ-B with BAI and DASS was calculated using Pearson correlations. The results of correlational analysis between W-DEQ-B and BAI $(r=0.160)$, DASS $(r=0.178)$ and by dimensions of DASS questionnaire including stress 
The New Indian Journal of OBGYN. 2021 (July-December);8(1)

Table 3: Correlations among the WDEQ version $B$ and the BAI and DASS

\begin{tabular}{lllllll}
\hline Parameters & WDEQ & BAI & DOSS & Stress & Anxiety & Depression \\
\hline WDEQ & 1 & $0.160^{*}$ & $0.178^{*}$ & $0.166^{*}$ & $0.151^{*}$ & $0.179^{*}$ \\
BAI & $0.160^{*}$ & 1 & $0.775^{*}$ & $0.689^{*}$ & $0.754^{*}$ & $0.712^{*}$ \\
DOSS & $0.178^{*}$ & $0.775^{*}$ & 1 & $0.952^{*}$ & $0.920^{*}$ & $0.904^{*}$ \\
Stress & $0.166^{*}$ & $0.689^{*}$ & $0.952^{*}$ & 1 & $0.812^{*}$ & $0.821^{*}$ \\
Anxiety & $0.151^{*}$ & $0.754^{*}$ & $0.920^{*}$ & $0.812^{*}$ & 1 & $0.723^{*}$ \\
Depression & $0.179^{*}$ & $0.712^{*}$ & $0.904^{*}$ & $0.821^{*}$ & $0.723^{*}$ & 1 \\
\hline * Correlation is significant at the 0.01 level (2-tailed). & &
\end{tabular}

$(\mathrm{r}=0.166)$, anxiety $(\mathrm{r}=0.151)$ and depression $(\mathrm{r}=0.179)$ indicated a significant correlation $(\mathrm{p} \leq 0.001)$ (table 3$)$.

Test-retest reliability: Thirty postpartum women were asked to check each item in the questionnaire twice as their experience in the same manner, at the first visit and then within a two-week period. The test-retest reliability of the scale was estimated by an intra-class correlation coefficient (ICC). The ICC for the WDEQ-B was 0.995 and for 6 subscales was as order: lack of positive feelings, 0.994; concerns about childbirth, 0.994; fear and pain, 0.961; concerns about childbirth, 0.989; loneliness, 0.988; lack of positive behaviors, 0.997 and concerns for the baby was 0993 ( $\mathrm{p}<0.05$, table 4).

Table 4: Test-retest reliability, Intra-class correlation (ICC) of the Persian W-DE

\begin{tabular}{ll}
\hline W-DEQ Scale & ICC \\
\hline Total & 0.995 \\
W-DEQ subscales & \\
Lack of positive feelings & 0.994 \\
Fear and pain & 0.961 \\
Concerns about childbirth & 0.989 \\
Loneliness & 0.988 \\
Lack of positive behaviors & 0.997 \\
\hline
\end{tabular}

\section{Discussion}

This study aimed to analyze the psychometric properties of the W-DEQ-B questionnaire in Iranian women. This paper reports the translation procedure, structure, validity and reliability of the W-DEQ in Iran. Our results revealed sixfactors which are lack of positive feelings, fear, and pain, concerns about childbirth, loneliness, lack of positive behaviors and concerns for the baby.

The validity and reliability of instruments with a conceptual and functional appropriateness into another language is a complex process and requires more researches. ${ }^{35}$ In the psychometric process, we used the guidelines for cross-cultural adjustment and obtained a cultural and conceptual equivalence of questionnaire, like the original version, then we can say the W-DEQ-B is culturally applicable to the Iranian women. In construct validity evaluation, the quantitative and qualitative face and content validity were used to take advantage of this combination. $^{36}$ Only minor changes in wording or descriptions of some items were made in the original version.

The CVI score for most items was $\geq 0.80$ and CVR results revealed that all items are necessary and important. In addition, EFA results supported the factorial structure with the six constructs reported by Korukcu et al. ${ }^{17}$ and Garthus-Niegel et al. ${ }^{15}$ The results reflected that the W-DEQ had adequate indicators for reliability and the internal consistency of all subscales was reasonable (alpha from 0.50 to 0.82 ). The reliability of the W-DEQ scale was 0.99 , similar to that reported by Wijma et al. (>0.90). Cronbach's $\alpha \geq 0.7$ was considered satisfactory for an internal consistency level. ${ }^{37}$ The test-retest reliability of the W-DEQ with a two-week interval was found to be high. Using the intraclass correlation coefficients test, all subscales achieved a high correlation $(>0.96)$, indicating that in a stable health state over time, the W-DEQ produces constant results from participants.

According to the searching by authors, there is no validated tool for measuring FOC after delivery in the postpartum period. The WEDQ version A for measuring FOC among pregnant women was translated and validated by Abedi et al in the Persian language. ${ }^{18}$ A study by Korukcu et al, in Turkey for testing the reliability and validity of WEDQ-B resulted in a six-factor solution including; concerns about pain, lack of positive behaviors, loneliness, lack of positive feelings, concerns about childbirth, and concerns about the baby. ${ }^{17}$ Our results are similar to Korukcu et al, except for fear and pain.

In the present study, we used BAI and DASS to test the concurrent validity of W-DEQ, but it is recommended that further researches including other scales to provide stronger support for concurrent validity should be conducted. Also, Wijma et al recruited women two times after delivery (2 hours and 5 weeks after delivery). ${ }^{38}$ Therefore, the Persian version of W-DEQ-B should be used with caution, because it tested only once in a 30-days period.

\section{Conclusion}

The Iranian version of the W-DEQ-B with the six-factor structure was approved through the qualitative and quantitative face and content validity, reliability, and acceptability for the target group. This scale will be useful in the reduction of fear of childbirth, improvements of normal vaginal delivery, reduction of CS and also detecting women who may be at risk of postpartum depression. 
Acknowledgement: We would like to thank the research affairs of Ahvaz Jundishapur University of Medical Sciences. The Project of this study with No. RHPRC-9420 was financially supported by the Ahvaz Jundishapur University of Medical Sciences, Ahvaz, Iran. Also, we would like to thank all women who participated in this study.

\section{Conflict of interest: None. Disclaimer: Nil.}

\section{References}

1. Bydlowski M, Raoul-Duval A. Un avater psychique méconnu de la puerpéralité: la névrose traumatique postobstétricale. Perspectives Psychiatriques 1978; 4: 321-8.

2. Azami Aghdash S, Ghojazadeh M, Dehdilani N, Mohammadi M, Aslaminabad R. Prevalence and Causes of Cesarean Section in Iran: Systematic Review and Meta-Analysis. Iran J Public Health 2014; 43: 545-55.

3. Karimi-Zarchi M, Ghane-Ezabadi M, Vafaienasab M, Dehghan A, Ghasemi F, Zaidabadi M, et al. Maternal mortality in Yazd Province, Iran. Electronic physician 2016; 8: 1949-54.

4. Rouhe H, Salmela-Aro K, Halmesmaki E, Saisto T. Fear of childbirth according to parity, gestational age, and obstetric history. BJOG. 2009; 116: 67-73.

5. Toohill J, Fenwick J, Gamble J, Creedy DK. Prevalence of childbirth fear in an Australian sample of pregnant women. BMC Pregnancy Childbirth. 2014; 14: 275.

6. Bhatia MS, Jhanjee A. Tokophobia: A dread of pregnancy. Ind Psychiatry J. 2012; 21(2): 158.

7. Størksen HT, Garthus-Niegel S, Adams SS, Vangen S, Eberhard-Gran M. Fear of childbirth and elective caesarean section: a population-based study. BMC Pregnancy Childbirth 2015; 15: 221.

8. Pazzagli C, Laghezza L, Capurso M, Sommella C, Lelli F, Mazzeschi C. Antecedents and consequences of fear of childbirth in nulliparous and parous women. Infant Ment Health J. 2015; 36: 62-74.

9. Haines HM, Rubertsson C, Pallant JF, Hildingsson I. The influence of women's fear, attitudes and beliefs of childbirth on mode and experience of birth. BMC Pregnancy Childbirth. 2012; 12: 55.

10. Ryding E, Wirfelt E, Wangborg IB, Sjogren B, Edman G. Personality and fear of childbirth. Acta Obstet Gynecol Scand. 2007; 68: 814-20.
11. Haines H, Pallant JF, Karlström A, Hildingsson I. Crosscultural comparison of levels of childbirth-related fear in an Australian and Swedish sample. Midwifery. 2011; 27: $560-7$

12. Laursen M, Hedegaard $M$, Johansen C. Fear of childbirth: predictors and temporal changes among nulliparous women in the Danish National Birth Cohort. BJOG. 2008; 115: 354-60.

13. Sydsjo G, Sydsjo A, Gunnervik C, Bladh M, Josefsson A. Obstetric outcome for women who received individualized treatment for fear of childbirth during pregnancy. Acta Obstet Gynecol Scand. 2012; 91:44-9.

14. Wijma K, Wijma B, Zar M. Psychometric aspects of the W-DEQ; a new questionnaire for the measurement of fear of childbirth. J Psychosom Obstet Gynaecol. 1998; 98:19, 84-97.

15. Garthus-Niegel S, Størksen HT, Torgersen L, VonSoest T, Eberhard-Gran M. The Wijma Delivery Expectancy/Experience Questionnaire: a factor analytic study. J Psychosom Obstet Gynaecol. 2011; 32: 160-3.

16. Takegata M, Haruna M, Matsuzaki M, Shiraishi M, Okano T, Elisabeth Severinsson E. Psychometric Evaluation of the Japanese Wijma Delivery Expectancy/ Experience Questionnaire Version B. Open J Nursing. 2017; 7: 15-27.

17. Korukcu O, Bulut O, Kukulu K. Psychometric Evaluation of the Wijma Delivery Expectancy/ Experience Questionnaire Version B. Health Care Women Int. 2016; 37: 550-67.

18. Abedi P, Hazeghi N, Afshari P, Fakhri A. The Validity and Reliability of Persian Version of Wijma Delivery Expectancy/Experience Questionnaire (Version A) among Iranian Nulliparous Women. Global J Health Sci. 2017; 9: 269-76

19. Polit D, Beck C. Nursing Research Generaing and assessing Evidence for Nursinf practice. 9 ed. Philadelphia: Lippincott Williams \& Wilkins; 2012. pp. 225-31.

20. Beck AT, Steer RA. Relationship between the Beck Anxiety Inventory and the Hamilton Anxiety Rating Scale with anxious outpatients. J Anxiety Disord. 1991; 5: 213-23.

21. Kaviani H, Mousavi AS. Psychometric properties of the Persian version of Beck Anxiety Inventory (BAI). Tehran Univ Med J. 2008; 66:136-40.

22. Asghari A, Saed F, Dibajnia P. Psychometric properties of the Depression Anxiety Stress Scale-21 (DASS-21) in 
The New Indian Journal of OBGYN. 2021 (July-December);8(1)

a non-clinical Iranian sample. Int J Psychol. 2008; 2: 82-102.

23. Kline P. A psychometrics primer. London: Free Assn books; 2000.

24. Ayre C, Scally AJ. Critical values for Lawshe's content validity ratio: revisiting the original methods of calculation. Meas Eval Couns Dev. 2014; 47: 79-86.

25. Lawshe $\mathrm{CH}$. A quantitative approach to content validity1. Pers Psychol. 1975; 28: 563-75.

26. Lynn MR. Determination and quantification of content validity. Nurs Res. 1986; 35: 382-5.

27. Polit DF, Beck CT. Nursing research: principles and methods. Philadelphia: Lippincott Williams \& Wilkins; 2004.

28. González-Manteiga W, Crujeiras RM. An updated review of goodness-of-fit tests for regression models. Test. 2013; 22: 361-411.

29. Revelle W. An introduction to psychometric theory with applications in R. Evanston: Department of Psychology, Northwestern University; 2013.

30. Hahs-Vaughn DL. Applied multivariate statistical concepts. New York: Taylor \& Francis; 2016.

31. Tavakol M, Dennick R. Making sense of Cronbach's alpha. Int J Med Educ. 2011; 2: 53.

32. Polit DF, Beck CT. Nursing research: Generating and assessing evidence for nursing practice. Philadelphia: Lippincott Williams \& Wilkins; 2008.

33. Lovibond PF, Lovibond SH. The structure of negative emotional states: Comparison of the Depression Anxiety Stress Scales (DASS) with the Beck Depression and Anxiety Inventories. Behav Res Ther. 1995; 33: 335-43.
34. Vet H. Observer reliability and agreement. Wiley Stats Ref: Statistics Reference Online. 2014.

35. Jones PS, Lee JW, Phillips LR, Zhang XE, Jaceldo KB. An adaptation of Brislin's translation model for crosscultural research. Nurs Res. 2001; 50: 300-4.

36. Hyrkas K, Jamir T, editors. Development and Validation of a Self-report Tool for Acute Hospital Patients Measuring Spiritual Aspects of Interpersonal Care. Philadelphia: Lippincott williams \& wilkins; 2019.

37. Bolarinwa OA. Principles and methods of validity and reliability testing of questionnaires used in social and health science researches. Niger Postgrad Med J. 2015; 22: 195.

38. Wijma K, Ryding EL, Wijma B. Predicting psychological well-being after emergency caesarean section: A preliminary study. J Reprod Infant Psychol. 2002; 20: 25-36.

Zahra Abbaspoor ${ }^{1}$, Mohammad Hosein Haghighizadeh ${ }^{2}$, Parvin Abedi $^{3}$

${ }^{1}$ PhD of Reproductive Health, Midwifery Department, Reproductive Health Promotion Research Center, Ahvaz Jundishapur University of Medical Sciences, Ahvaz, Iran; ${ }^{2}$ Department of Statistics, School of Public Health, Ahvaz Jundishapur University of Medical Sciences, Ahvaz, Iran; ${ }^{3}$ PhD of Community Nutrition, Midwifery Department, Menopause \& Andropause Research Center, Ahvaz Jundishapur University of Medical Sciences, Ahvaz, Iran. 